\title{
Psychosocial reactions of Pakistani Students towards COVID-19: A prevalence study
}

\author{
Zahid Mahmood', Sadia Saleem², \\ Sara Subhan ${ }^{3}$, Ayesha Jabeen ${ }^{4}$
}

\begin{abstract}
Background: The current study aimed at investigating the manifestation and prevalence of the commonly reported psychosocial reactions in the university students following the onset of COVID-19 pandemic.

Methods: This cross-sectional survey was carried out during April to May, 2020 in the city of Lahore. Based on the interviews and presenting problems of thirty-nine self-referred students to student counselling service center, a list of twenty-seven self-report measure was presented through an online cross-sectional survey of 510 students enrolled in a private institute. The age range of the participants was between 17-26 years $(M, 21.86$; $S D, 2.94)$.

Results: The results showed that the most frequently reported reactions by university students during COVID-19 is restricted daily routine (92\%), preoccupation with cleanliness (86\%), feeling uncertain about future (85\%), feeling bored (84\%) and low mood (84\%). The least frequently reported reaction was financial crisis (48\%). The findings further showed that $18 \%$ of the participants had mild, $34 \%$ had moderate, $29 \%$ severe and $19 \%$ very severe level of problems.

Conclusions: The finding revealed that university students have significantly affected by this pandemic which need attention from mental health professionals.
\end{abstract}

KEYWORDS: Depression, Anxiety, COVID-19, Students.

doi: https://doi.org/10.12669/pjms.37.2.3063

How to cite this:

Mahmood Z, Saleem S, Subhan S, Jabeen A. Psychosocial reactions of Pakistani Students towards COVID-19: A prevalence study. Pak J Med Sci. 2021;37(2):456-460. doi: https://doi.org/10.12669/pjms.37.2.3063

This is an Open Access article distributed under the terms of the Creative Commons Attribution License (http://creativecommons.org/licenses/by/3.0), which permits unrestricted use, distribution, and reproduction in any medium, provided the original work is properly cited.

\section{INTRODUCTION}

1. Zahid Mahmood, PhD.

2. Sadia Saleem, PhD.

3. Sara Subhan, PhD.

4. Ayesha Jabeen,

1-4: Department of Clinical Psychology,

under School of Professional Psychology,

University of Management and Technology,

Lahore, Pakistan.

Correspondence:

Ayesha Jabeen

Department of Clinical Psychology,

under School of Professional Psychology,

University of Management and Technology,

Lahore, Pakistan.

Email: ayesha.jabeen@umt.edu.pk

* Received for Publication:

June 26, 2020

* $1^{\text {st }}$ Revision Received:

* $2^{\text {nd }}$ Revision Received:

* Final Revision Accepted:
August 15, 2020

December 9, 2020

December 16, 2020
The recent upsurge of fear, panic, and uncertainty caused by the rapid and dramatic spread of Coronavirus across all continents, countries, and communities has shaken our sense of safety and security. ${ }^{1}$ Corona virus reached in Pakistan by the end of February 2020 and complete lockdown was observed on $23^{\text {rd }}$ March, 2020 resulting in the closure of most of the industries and educational institutes. ${ }^{2}$ The magnitude of the problems caused by Corona- 19 and its rates of spreading has caught us unprepared. We are all going through a difficult time emotionally, socially and educationally. ${ }^{3}$ University years are considered as one of the most crucial time periods in intellectual and psychological sense. University life demands extensive cognitive input, opportunity to make intimate relationships, explore career opportunities and meet expectations 
of parents. ${ }^{4}$ All these pressures requires a continuous phase of adjustment which may make them vulnerable to experience mental health issues. As performance of the students largely depends on their mental health therefore any deterioration may bring negative impacts to the individual and society..$^{5}$ In 2011, a survey of mental health problems in a sample of 1850 university students of Lahore, Pakistan revealed that $31 \%$ of the participants fall in "sever" category, and 16\% fall in "very severe" category of psychological issues. ${ }^{6}$

In current circumstances, students are reeling under the impact of pandemic which is a topic of attention worldwide. Particularly, in underdeveloped countries like Pakistan where lack of facilities and training of online education system has challenged the stakeholders academically and emotionally. ${ }^{3}$ Traditional education system with face to face teaching tied student-teacher interaction in social and emotion bond which seemed threatened in an online education system. ${ }^{7}$ The impact of this calamity has attained greater attention from the researchers and been associated with various mental health consequences. ${ }^{8}$ The fear of this pandemic which is causing many deaths has significantly changed our lives, inculcated a sense of fear and dramatically restricted our personal and social lives to curtail its spread. ${ }^{9}$ University students were at different phases of their education when sudden lockdown happened. Some were ready to appear in their final examination, some just started their semester, and other were ready to go to the field to get practical exposure. ${ }^{10}$ The uncertainty about the prevailing situation geared up stress in students. Apprehensions about online education system, financial crisis and concerns of parents about the future of their children was an add-on to stress. ${ }^{11}$

Researches have shown that lack of personal space at home, imposed social distancing with class mates, inability to interact with peers, friends and teacher's in-person, limited access to educational resources, led the students to experience boredom and frustration. ${ }^{7,8}$ A paradigm shift in education system due to pandemic anticipated uncertainties about future in students. A plethora of research evidence revealed that chronic illness may aggravate mental health problems like depression, anxiety and posttraumatic stress. ${ }^{12}$ The available literature reveals that anxiety, depression, stress, poor sleep, and suicidal ideation are the most common psychological problems reported by general people and professionals. ${ }^{13,14}$
The psychological states caused by sudden, unexpected and frightening experiences can often lead to clouding of critical faculties by bias, prejudice, irrational attitudes that in turn is likely to worsen the problem. ${ }^{15}$ Therefore, it is very pertinent to explore the experience and expression of psychological reactions developed by students, who not only been feeling panicky and fearful but also had to undergo restricted social activities and social lockdown which eventually exacerbate their suffering and symptoms of distress. ${ }^{16}$ Such experiences limit their resources to cope with this pandemic. The early identification of people at risk of serious mental health problems can facilitate timely intervention. ${ }^{17}$

The current research, therefore, aimed to explore the commonly reported psychosocial reactions of university students in this widespread outbreak of COVID-19 so that tailormade psychological intervention can be planned and provided timely to manage and cope with the adverse consequences of COVID-19.

\section{METHODS}

A sample of 510 graduate students (men $39.60 \%$ and $60.40 \%$ women) participated through an online survey studying in a private university of city Lahore (Pakistan) during April to May, 2020. The age range was between 17-26 years with mean age $21.86+2.94$ participated in the survey Table-I. Participants being unmarried, having access to internet and with ability to understand English was included in the study using purposive sampling technique.

Total 344 participants $(68 \%)$ belonged to nuclear family system and 161 (32\%) belonged to joint family system. Most of the parents of the participants had high level of education and only about $30 \%$ had minimum education up to Middle level. Approval from Institutional Ethical Committee was taken (IRB No. 201905-010, dated 03-05-2020) Written informed consent was taken from participants through email, they were ensured about confidentiality, anonymity and were given right to withdraw during interview. The measure of the current study comprised a Demographic Form reporting age, gender, educational level and the living system. A self-report likert-type measure, the Psychosocial Reaction Scale (PRS) comprising 27 items based on the presenting problems of 39 self-referred students at the Counselling Service Center during COVID-19 lockdown period in 


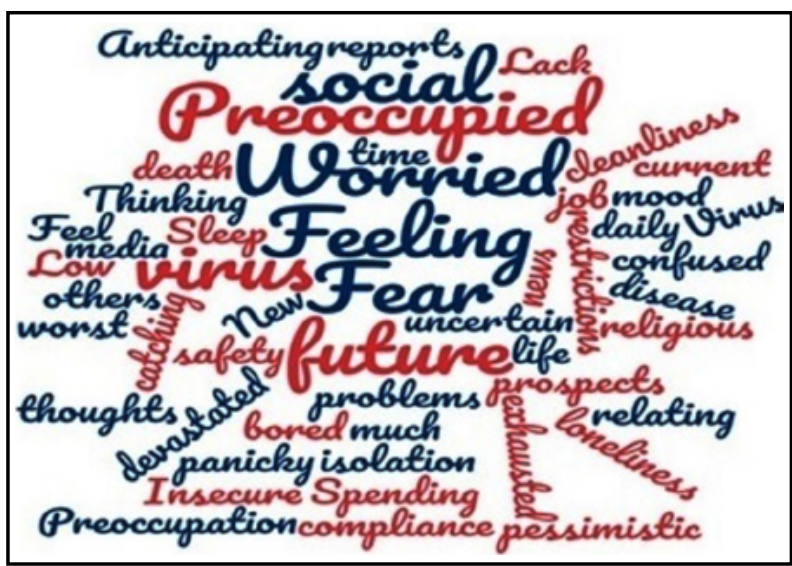

Fig.1: Pictorial Description of Psychosocial Reactions Experienced by Students during COVID-19.

Pakistan. The response options include 0 (not at all), 1(a little), 2(to some extent), and 3(a lot). Participants were asked to rate each statement to the extent to which it applies to them. The scoring range is between 0 to 81 , higher score denotes to more psychosocial reactions experienced by university students. The Cronbach alpha for the current research is .92 showing a high internal consistency of PRS. Results were analyzed by using IBM SPSSV21.0, World cloud was used to highlight the themes from verbatim given in interviews of students.

\section{RESULTS}

A pictorial description of the frequently reported psychosocial reactions expressed by university students is presented in Fig.1.

The prevalence rate of psychosocial reactions was determined by deriving the participants' total score on PSR. The sample was divided into four categories of severity of according to means and the standard deviations in the following manner. These four categories are mild ( 1 SD below the mean), moderate (mean), severe ( $1 S D$ above the mean) and very severe (2SD above the mean).

Table-I shows that restricted daily routine, preoccupation with cleanliness, feeling uncertain about the future and low mood, boredom, anticipating the worst news were at the top of the list. Table-II

Prevalence of Psychosocial Reactions: The prevalence of psychosocial reactions was determined by deriving the participants' total score on PSR. The sample was divided into four categories of severity of according to means and the standard deviations in the following manner.

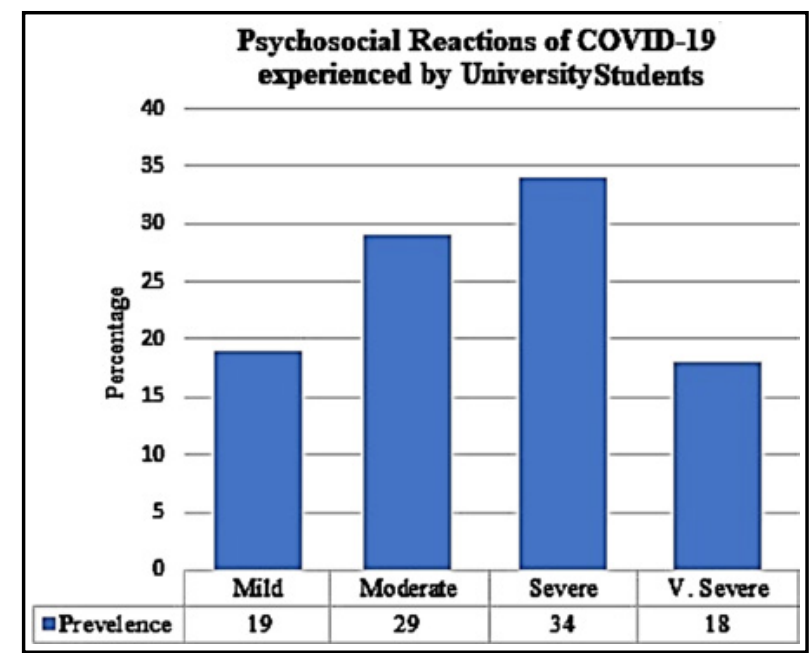

Fig.2: Distribution of the Participants $(\mathrm{N}=510)$ on Severity of PSPS Score.

These four categories are mild (1 SD below the mean), moderate (mean), severe ( $1 S D$ above the mean) and very severe (2 SD above the mean).

However, Independent sample $t$-test showed non-significant results with respect to gender and family system in their experience of psychosocial reactions.

\section{DISCUSSION}

The pandemic of COVID-19 spread so quickly that world was not prepared and ready to understand it. Until very recently, very few mental health professionals had undertaken serious

Table-I: Frequency and Percentage of Demographic Variables of Participants $(\mathrm{N}=510)$.

\begin{tabular}{lcc}
\hline Variables & $f$ & $\%$ \\
\hline Age & & \\
$18-21$ & 273 & 53.50 \\
$22-27$ & 237 & 46.50 \\
Gender & & \\
Men & 202 & 39.60 \\
Women & 308 & 60.40 \\
Class & & \\
BS1 & 90 & 17.60 \\
BSII & 93 & 18.20 \\
BSIII & 58 & 11.40 \\
BSIV & 102 & 20.00 \\
MS I \& II & 167 & 33.01 \\
Family System & & \\
Nuclear & 347 & 68.00 \\
Joint & 163 & 32.00 \\
\hline
\end{tabular}

Note: $f$ : Frequency, \%: Percentage. 
Table-II: Frequency of most Frequently Reported Psychosocial Reactions (N=510).

\begin{tabular}{llll}
\hline Item & Items & $f$ & $\%$ \\
No. & & & \\
\hline 23 & Restricted daily routine & 471 & 92 \\
22 & Preoccupied with cleanliness & 439 & 86 \\
5 & Feeling uncertain about the future & 436 & 85 \\
3 & Feeling bored & 428 & 84 \\
7 & Low mood & 428 & 84 \\
18 & Anticipating the worst news & 427 & 84 \\
24 & Worried about job prospects & 421 & 83 \\
27 & Spending more time on & 421 & 83 \\
& social media reports & & \\
4 & Fear of catching the disease & 414 & 81 \\
1 & Feeling confused & 403 & 79 \\
8 & Feeling pessimistic about the future. & 387 & 76 \\
14 & Lack of compliance by others & 381 & 75 \\
26 & Feeling exhausted & 384 & 75 \\
15 & Fear of loneliness & 375 & 74 \\
19 & Feeling devastated & 378 & 74 \\
2 & Insecure & 362 & 71 \\
10 & Worried about own safety & 364 & 71 \\
11 & Feeling aches and pains & 364 & 71 \\
17 & Worried about the future & 362 & 71 \\
20 & Fear of death & 347 & 68 \\
25 & Preoccupied with “what if...” & 348 & 68 \\
6 & Sleep problems & 346 & 67 \\
9 & Feeling panicky & 339 & 66 \\
13 & Feel social isolation & 314 & 62 \\
15 & Preoccupation with thoughts & 280 & 55 \\
& relating to the current virus & & \\
21 & Becoming more religious & 250 & 49 \\
12 & Financial crisis & 247 & 48 \\
\hline & &
\end{tabular}

scientific studies to understand the psychological impact of COVID-19 and a limited research is available to understand the magnitude of the psychosocial reactions experienced and expressed by this unpredictable situation. Pakistan is an under developing country that has limited health care facilities, low education and lack of awareness have created more panic and fear of the situation and sudden lockdown and social distancing have created stress and anxiety. ${ }^{8}$

Contrary to other correlational studies, the current study is an attempt to identify the nature, pattern, and magnitude of the psychosocial problems experienced by university students as a result of COVID-19. The first consideration of the current research was to use tailor-made assessment procedures rather than frequently used anxiety and depression measures developed in other contexts and on another set of samples. We used an open-ended approach by collating a list of the most frequently reported reactions of the self-referred individual in the counselling service. This gives us a contextually and ecologically valid yardstick to measure the psychological impact of COVID-19. The overall picture of the presenting problem is in line with the existing literature. ${ }^{1,9}$ These problems give a picture of depressive features, a sense of apprehensions, and fear of unknown, panic and so on.

Results of the current study have revealed that the topmost problem reported by students is restricted daily routine which represents the major hurdle of university years. ${ }^{3}$ During normal circumstances, university students have a very active personal, academic and social life that also plays the role of a coping mechanism to handle daily life stressors and having to adjust with a new way of life. ${ }^{14}$ The second most frequently reported problem was the preoccupation with cleanliness; bearing in mind that cleanliness has a very special function in our culture in everyday life where they have to wash their hands before and after every meal and to perform ablution five times a day. This is also because of a constant campaign through social media to raise awareness about the precautionary measures to prevent oneself from COVID-19. The third most frequently reported problem is feeling uncertain about the future indicates a sense of apprehensions and anxiety .This may be because of the lack of knowledge about the disease and not having any tangible remedy specifically used for COVID-19. Contrary to western literature, financial issues doesn't appear very prominently because in Pakistani context, usually parents are responsible for children's education often at graduate and postgraduate level. ${ }^{4}$

The prevalence rate is alarming in nature and a large number of university students have been suffering from mental health concerns. ${ }^{18}$ Almost half the respondent need psychological first aid in one way or the other. It is important to note that in a short time our life has been turned upside down, changing our view of ourselves and the world. From a relatively safe and predictable living, we are now afraid to think of our future. Such anxieties are a natural reaction because of the fact of how events unfolded. At a time of sudden and severe stress, we observe two extreme reactions. ${ }^{19,20}$ Some overreact with panic measures and others deny the danger and perhaps pretend nothing is going to happen to them. Most of us move 
from one reaction to the other ${ }^{21}$. This situation of uncertainty arises especially when we do not have enough information to form a realistic view of the problem and our reaction. There is a great need for comprehensive and cohesive need-based services to address the arising state of confusion and uncertainty. Future research also focused on different segments of populations so the mental health services can be expanded.

Limitations of the study: The study represented the experiences of students who had availability of internet, smart phones and email addresses. However, it may not be representative of the issues of students having lack of such facilities.

\section{CONCLUSIONS}

The results of the study revealed that COVID-19 pandemic affected students cognitively, behaviorally and socially. The psychological symptoms measured by indigenous measure reflected high prevalence of these issues indicating the dire need of intervention.

\section{Grant Support \& Financial Disclosures: None.}

\section{REFERENCES}

1. Grubic N, Badovinac S, Johri AM. Student mental health in the midst of the COVID-19 pandemic: A call for further research and immediate solutions. Int J Soc Psychiatry. 2020;66(5):517-518. doi: 10.1177/0020764020925108

2. Kaleem MF. 2020. Educational institutions to stay closed till July 15; board exams cancelled. https://dailytimes. com.pk/609118/educational-institutions-to-stayclosed-till-july-15-boardexams-cancelled/ (accessed 12 May 2020).

3. Mukhtar K, Javed K, Arooj M, Sethi A. Advantages, Limitations and Recommendations for online learning during COVID-19 pandemic era. Pak J Med Sci. 2020;36(COVID19-S4):COVID19-S27-S31. doi: 10.12669/ pjms.36.COVID19-S4.2785

4. Azhar M, Saleem, M, Mahmood Z. Perceived Parenting and Distress Tolerance as Predictors of Mental Health Problems in University Students. J Res in Soc Sci. 2020;8(1):91-105.

5. Syed A, Ali SS, Khan M. Frequency of depression, anxiety and stress among the undergraduate physiotherapy students. Pak J Med Sci. 2018;34(2):468-471. doi: 10.12669/ pjms.342.12298

6. Saleem S, Mahmood Z. Naz M. Mental health problems in university students: A prevalence study. FWU J Soc Sci. 2013;(7)2:124-130.

7. Khan S, Khan M, Maqsood K, Hussain T, Noor-ul-Huda, Zeeshan M. Is Pakistan prepared for the COVID-19 epidemic? A questionnaire-based survey. J Med Virol. 2020;92:824-832. doi: 10.1002/jmv.25814

8. Goothy SSK, Goothy S, Choudhary A. COVID-19 lockdown impact on the mental health of students: need to start a mental health cell. MOJ Anat Physiol. 2020;7(2):51-52. doi: 10.15406/mojap.2020.07.00289
9. DanielSJ.Education and the COVID-19 pandemic. Prospects, 2020. doi: $10.1007 /$ s11125-020-09464-3

10. Bao Y, Sun Y, Meng S, Shi J, Lu L. 2019-nCoV epidemic: Address mental health care to empower society. Lancet. 2020;22(395):e37-e38.

11. Rajkumar RP. COVID-19 and mental health: A review of the existing literature. Asian J Psychiatr. 2020;52:102066.

12. Wang C, Pan R, Wan X, Tan $Y, X u$ L, Ho CS, et al. Immediate psychological responses and associated factors during the initial stage of the 2019 coronavirus disease (COVID-19) epidemic among the general population in China. Int J Environ Res Public Health. 2020;17(5):E1729.

13. Haider II, Tiwana F, Tahir SM. Impact of the COVID-19 Pandemic on Adult Mental Health. Pak J Med Sci. 2020;36(COVID19-S4):COVID19-S90-S94. doi: 10.12669/ pjms.36.COVID19-S4.2756

14. Mukhtar F, Mukhtar N. Coronavirus (COVID-19): Let's Prevent Not Panic. J Ayub Med Coll. 2020;32(1):141-144.

15. Adhikari SP, Meng S, Wu YJ, Mao YP, Ye RX, Wang QZ, et al. Epidemiology, causes, clinical manifestation and diagnosis, prevention and control of coronavirus disease (COVID-19) during the early outbreak period: A scoping review. Infect. Dis. Poverty 2020;17(9):29.

16. Pakistan Coronavirus: 7,025 Cases and 135 DeathsWorldometer [Internet]. Worldometers.info. 2020 [cited 22 April 2020]. Available from Available from: https://www. worldometers.info/coronavirus/country/pakistan/

17. Kumar SC. Awareness, benefits and challenges of e-learning among the students of Kurukshetra University Kurukshetra: A study. Int J Inf Dissemination Tech. 2019;8(4):227-230. doi: 10.5958/2249-5576.2018.00048.1

18. Fardin MA. COVID-19 and Anxiety: A Review of Psychological Impacts of Infectious Disease Outbreaks, Archive of Clinical Infectious Disease. Online ahead of Print; 15(COVID-19):e102779. doi: 10.5812/archcid.102779.

19. Gunathilaka N, Chandradasa M, Champika L, Siriwardana S, Wijesooriya L. (2018).Delayed anxiety and depressive morbidity among dengue patients in a multi ethnic urban setting: First report from Sri Lanka. Int J of Ment Health Syst, 2018;12:20-27. doi: 10.1186/s13033-018-0202-6

20. Zandifar A, Badrfam R. Iranian mental health during the COVID-19 epidemic. Asian J Psychiatr. 202051:101990.

21. Ashraf F, Lee SA, Elizabeth Crunk A. Factorial validity of the Urdu version of the Obsession with COVID-19 Scale: Preliminary investigation using a university sample in Pakistan. Death Stud. 2020;18:1-6. doi: 10.1080/07481187.2020.1779436. (Epub ahead of print).

\section{Authors Contribution:}

ZM: Supervised the project and is responsible and accountable for the accuracy or integrity of the work.

SS: Prepared the manuscript and enhanced conceptual understanding

SS: Prepared the google doc, carried out initial statistical analysis, data collection

AJ: Provided statistical support and also reviewed the document. 